\title{
The interplay of dynamic and thermodynamic processes in driving the ice-edge location in the Southern Ocean
}

\author{
R.P. STEVENS, ${ }^{1}$ P. HEIL ${ }^{2}$ \\ ${ }^{1}$ Institute for Marine and Antarctic Studies and Antarctic Climate and Ecosystems CRC, University of Tasmania, \\ Private Bag 80, Hobart, Tasmania 7001, Australia \\ E-mail: Roger.Stevens@utas.edu.au \\ ${ }^{2}$ Australian Antarctic Division and Antarctic Climate and Ecosystems CRC, University of Tasmania, Private Bag 80, Hobart, \\ Tasmania 7001, Australia
}

\begin{abstract}
A stand-alone sea-ice model (CICE4) was used to investigate the physical processes affecting the ice-edge location. Particular attention is paid to the relative contributions of dynamic and thermodynamic processes in advancing the ice edge equatorward during ice growth. Results from 10 years of an 11 year numerical simulation have been verified against satellite observations from 1998 to 2007. The autumn advance of the sea-ice edge is primarily due to thermodynamic processes, with significant dynamic contributions limited to regions such as $60-70^{\circ} \mathrm{E}$ and $310-340^{\circ} \mathrm{E}$. In the dynamically dominated regions, winds with a southerly component cause equatorward ice advection but also induce thermodynamic growth of new ice, which occurs well poleward of the $15 \%$ iceconcentration contour where air temperature is lowest. As the ice moves into warmer water it melts, hence extending equatorward the region with ocean mixed layer at freezing point. This accelerates the northward progression of the ice edge and permits thermodynamic ice growth as soon as the air temperature reaches below the ocean freezing point. In regions where thermodynamic processes are dominant (e.g. $340-40^{\circ} \mathrm{E}$ ), maximum ice production occurs just poleward of the $15 \%$ ice-concentration contour, where thin sea ice is prevalent. In these longitude bands, autumn ice melt is generally absent at the ice edge due to ineffective equatorward ice advection.
\end{abstract}

\section{INTRODUCTION}

The sea-ice cover and its seasonal and interannual variability are important components of the Antarctic climate system. Sea ice modifies the energy and mass fluxes between atmosphere and ocean, and dramatically affects the radiation balance at the Earth's surface (e.g. Ebert and Curry, 1993). Seasonal and interannual variability in sea-ice extent also affect the regional primary production via the amount of ice algae which can be supported in the sea ice (Thomas and Dieckmann, 2009). Furthermore, variability in the ice extent causes changes in the ice and under-ice fauna. For example, in years when the winter sea-ice extent is extensive, there are few salps, and spawning of krill is promoted (Loeb and others, 1997). To identify the driving forces of interannual variability in zooplankton, we need to account for interannual variability in sea-ice extent, and hence understand the processes controlling the ice extent.

Sea-ice extent itself is determined by both the dynamic process of ice advection and the balance between thermodynamic ice growth and melt. A systematic analysis of contributing processes is best carried out using a numerical model, which explicitly includes the relevant processes. Generally such modelling studies have been focused on the Northern Hemisphere or have been conducted at relatively low spatial resolution (Bitz and others, 2005). Studying the effect of including an ice-thickness distribution compared to a single ice-thickness class, Holland and others (2006) found that the Southern Hemisphere sea-ice zone expanded. Their results showed a stark equatorward increase of sea ice in the Weddell Sea sector, which, however, was related to an overestimation of ice thickness in the eastern Weddell Sea. They did not provide information on the interannual variability in sea-ice extent in their study. Here we quantify the contribution of sea-ice dynamics relative to ice thermodynamics in moving the sea-ice edge equatorward during the ice growth season using a high-resolution stand-alone sea-ice model. This investigation is carried out by comparing the speed with which the modelled ice edge moves north with the meridional component of the modelled sea-ice velocity.

\section{METHOD AND DATA}

Definition of terms:

ice edge: in this study the location of the $0.1 \%$ ice concentration contour;

sea-ice extent: the area within the ice-ocean margin (Lubin and Massom, 2006);

sea-ice area: the area of ice-covered ocean (Lubin and Massom, 2006);

sea-ice concentration: the areal fraction or percentage of sea ice present within a given area (Lubin and Massom, 2006);

meridional sea-ice edge speed: the distance the ice edge at a particular longitude moves north during a unit of time; a northward transition is positive;

local freezing point: calculated for each gridcell as $0^{\circ} \mathrm{C}-(0.054 \times$ salinity $)$.

The ice edge can be defined in a number of ways but generally it is given as the most equatorward $15 \%$ iceconcentration contour. This is somewhat arbitrary and reflects the practical limits in deriving ice concentration 
Table 1. Sample of monthly MLD optimized to minimize difference between daily modelled ice area and SSM/I derived ice area

\begin{tabular}{|c|c|c|c|c|c|c|c|c|c|c|c|c|}
\hline Year & Jan & Feb & Mar & Apr & May & Jun & Jul & Aug & Sep & Oct & Nov & Dec \\
\hline 1998 & 25 & 5 & 20 & 29 & 42 & 57 & 93 & 220 & 430 & 400 & 20 & 10 \\
\hline 1999 & 20 & 5 & 15 & 29 & 39 & 78 & 120 & 250 & 450 & 400 & 40 & 10 \\
\hline 2000 & 20 & 5 & 22 & 26 & 35 & 79 & 130 & 280 & 550 & 500 & 60 & 10 \\
\hline
\end{tabular}

from satellite ice imagery. Model output does not suffer from such constraints, so in this paper the ice edge is defined by an ice concentration of $0.1 \%$. This was chosen not only because the contour includes almost all the gridcells which contain ice, but also because many of the processes examined here occur north of the model's $15 \%$ ice concentration contour.

The numerical model used here is based on Community Ice CodE (CICE)4 (Hunke and Dukowicz, 2002) where we configured the model to run in stand-alone mode on a highresolution Southern Ocean grid. The maximum gridcell size is $27.80 \mathrm{~km} \times 27.78 \mathrm{~km}$ and the minimum is $27.80 \mathrm{~km}$ $\times 18.18 \mathrm{~km}$. The land mask is based on the Moderate Resolution Imaging Spectroradiometer (MODIS) Mosaic of Antarctica (Scambos and others, 2007).

The atmospheric forcing is from the high-resolution PolarLAPS model (N. Adams, http://www.scires.com/divisions/meeting2009/agenda.htm). Three-hourly data of atmospheric surface temperature, pressure and humidity, downward shortwave radiation, cloud cover, precipitation and wind velocity were used to force the CICE4 model. Atmospheric forcing data are available from January 1998 to December 2008 inclusive, and are on the same grid as our model.

The oceanic forcing is provided by a simulation of the Australian Climate Ocean Model (AusCOM), which is a system still under development, and using the Modular Ocean Model version 4 (Griffies and others, 2004) with a three-layer sea-ice model (Winton, 2000), coupled by OASIS (Redler and others, 2010). The sea-ice model in the updated AusCOM is CICE4. AusCOM simulations provided monthly fields of sea-surface salinity and height, and surface currents. Oceanic forcing data were available from January 1998 to November 2006 inclusive. To simulate sea ice over the full length of atmospheric forcing data, a monthly climatology of the mean of 1998-2005 was used to force 2006-08. Atmospheric and oceanic forcing data are interpolated by nearest neighbour to the hourly model time-step. Prior to the actual 11 year simulation the model was spun up to equilibrium for 5 years using 1998 forcing.

The sea-ice model was set up to calculate internally the upward short- and longwave radiation, as a function of the surface albedo. Furthermore, the pronounced dependency of the modelled sea-ice extent and concentration on sea surface temperature (SST) showed that it was impossible to obtain reasonable sea-ice distributions when the model was forced by SST provided by either the atmosphere or the ocean simulation. Therefore the model was configured to calculate SST via a simple representation of the ocean as a slab parameterized by a mixed-layer depth (MLD). This allowed thermodynamic feedback between ice and ocean and greatly improved the skill of the model, especially with regard to seaice distribution. While the MLD is constant in space, the model was modified to allow for a temporarily variable MLD.
The MLD was varied between 5 and $500 \mathrm{~m}$ by minimizing the difference in daily ice area between our model output and observed Special Sensor Microwave/Imager (SSM/I) data (Comiso and Nishio, 2009). An optimum set of MLD was obtained for each month of each year modelled. Examples (Table 1) give an idea of the seasonal and interannual variation in derived MLD. The process of obtaining optimum MLDs was iterative, starting with a set of widely varying values and refining these to smaller ranges in subsequent simulations. It should be noted that the behaviour of the modelled ice area is complex and there are months when it is sensitive to MLD (March-August) and others when it is much less so (e.g. September-January) (Table 1). Furthermore the effect of MLD is inverted during ice retreat compared to ice growth. The 'changeover' points are in November and February. Lastly there appears to be a type of inertia to the response of ice area to changes in MLD, so refining MLD values requires consideration of previous and subsequent months. While the oceanic forcing includes surface currents, these interact only with the ice to contribute to ice advection. The currents do not advect oceanic heat or mass.

CICE4 uses the Arakawa-B grid and represents sea ice in each gridcell through an ice-thickness distribution function, g. Using a finite-difference approach it solves the equation

$$
\frac{\partial g}{\partial t}=-\nabla \cdot(g \mathbf{u})-\frac{\partial}{\partial h}(f g)+\psi,
$$

where $h$ is the ice thickness, $t$ is time, $\mathbf{u}$ is the horizontal ice velocity, $f$ is the thermodynamic growth rate, and $\psi$ is the ridging redistribution function. The model was run with five ice-thickness categories.

In the model numerics, sea ice is advected via incremental remapping (Lipscomb and Hunke, 2004), and, to save computational overhead, ice advection is calculated only for gridcells which contain ice above a specified minimum amount (thickness and concentration). Ice stress is calculated by an elastic-viscous-plastic rheology (Hunke and Dukowicz, 1997), and sea ice is free to respond with ridging to compressive stresses associated with convergent flow and the formation of leads, if the flow is divergent. The model moves ice in response to the forces of (1) drag between ice and atmosphere, (2) drag between ice and ocean, (3) gravity due to sea surface tilt, and (4) internal ice stresses.

The operation of CICE4 can be explained by examining a gridcell containing only ocean with a mixed layer above the local freezing point. An updated SST is determined via an energy flux calculation, which includes incoming and outgoing radiation, sensible and latent heat. Heat is exchanged between the ocean and atmosphere and between the mixed layer and the deep ocean. If the net heat transport is out of the mixed layer, then its temperature will decrease. This can continue until the energy removed from the mixed layer will cause its temperature to fall below the local freezing point. At this point, the model-internal quantity 


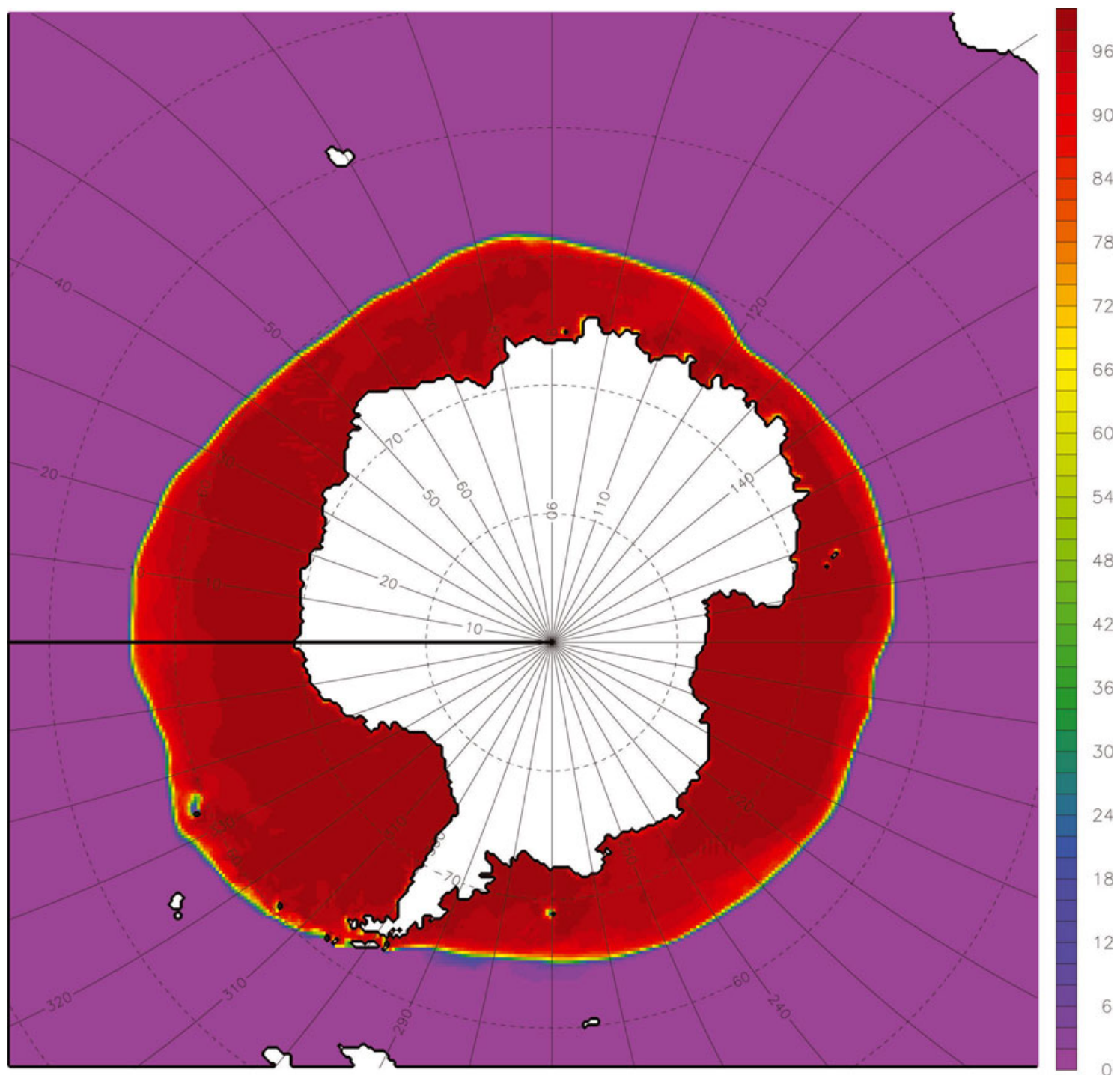

Fig. 1. Ice concentration near maximum ice extent on 30 September 2004.

freezing/melting potential determines the amount of thermodynamic ice growth.

The amount of ice grown or ablated depends on the freezing/melting potential. If the freezing/melting potential is positive, ice is formed and, if negative, ice melts. In the model, thermodynamic ice growth includes the production of frazil ice and congelation ice. Ice decay occurs via bottom, top and lateral melt. Positive freezing/melting potential in a gridcell containing open water causes the growth of frazil ice within the water column, which then floats to the ocean surface. There it is added to the thinnest ice category if possible. Excess ice is evenly distributed over the gridcell. Frazil production requires open water, hence it is found in the marginal ice zone (MIZ), in regions with open water leads and in coastal polynyas.

If the freezing/melting potential is positive where there is already sea ice, then growth is via congelation ice. Ice is added preferentially to the thinnest ice category. Congelation ice is the dominant form of ice growth in our simulations to date, because of the high ice concentrations that are the norm within the pack in the simulation.

To quantify the contribution of advection (dynamics) in moving the ice edge equatorward during the ice growth season, we compared the northward speed of the ice edge with the meridional sea-ice velocity. If the meridional velocity of the sea ice is less than or equal to the northward speed of the ice edge then thermodynamic processes are important. However, if the meridional ice velocity is greater than the speed of the ice edge, then the ice edge is largely driven equatorward by ice advection from the south. Equatorward advection moves sea ice into water with temperatures above the local sea-water freezing point, consequently inducing melt on the base and at the sides. Given sufficient ice melt, this causes the mixed layer to cool to the local freezing-point temperature, thereby creating the conditions necessary for subsequent thermodynamic ice growth, provided the surface air temperature is below the local freezing point.

The speed of the equatorward movement of the ice edge was calculated by measuring the distance (in metres) the ice edge moved during 8 day intervals and dividing by the number of seconds in 8 days. The 8 day interval was chosen because it was sufficiently large to produce measurable iceedge displacements and because it was larger than the synoptic-scale period at which most weather systems cross the Southern Ocean.

The meridional ice velocity was calculated by first converting ice velocity into a north-south and east-west 


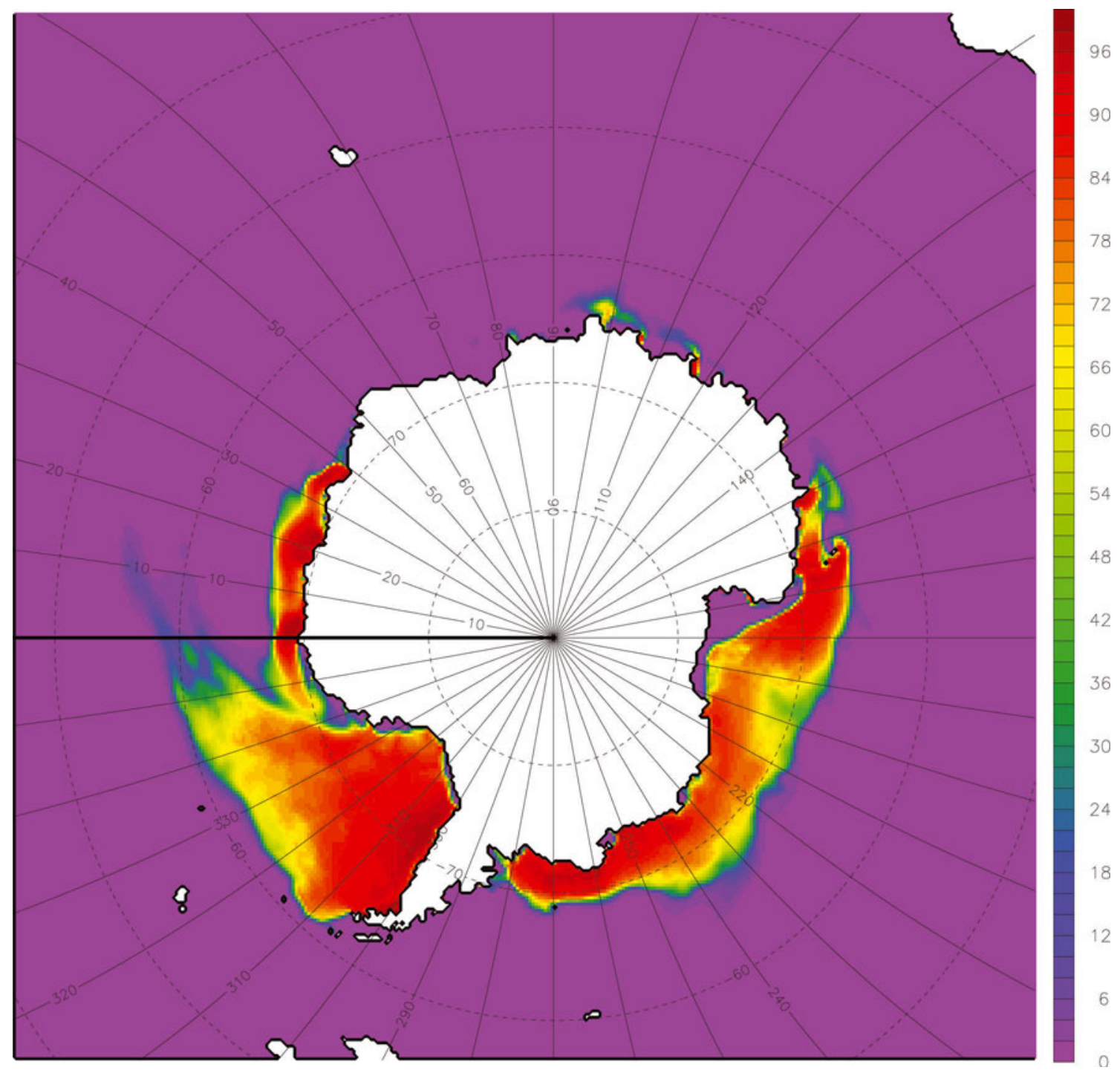

Fig. 2. Ice concentration near minimum ice extent on 20 February 2004.

coordinate system and then averaging the north-south velocity component of ice between the $0.1 \%$ and $60 \%$ ice concentration contours over the 8 day interval corresponding to the edge speed calculation. Ice in the $0.1-60 \%$ range was used because (1) it selects only ice near the ice edge in autumn and winter and (2) it includes sufficient ice to allow a velocity to be determined even for a very narrow MIZ. The comparison of the northward speed of the ice edge with the northward velocity of the sea ice is shown at intervals of $10^{\circ}$ of longitude.

In addition to data used to drive the sea-ice model, we also need data to assess the model performance. For this we use passive microwave satellite observations (Comiso and Nishio, 2009), available from 1998 to 2007.

\section{RESULTS}

Here we discuss the simulated sea-ice fields and provide information on the performance of our model set-up by comparison of model output with observed fields. The section concludes with our investigation to quantify the dynamic and thermodynamic contributions to the equatorward ice-edge relocation in austral autumn.

\section{Annual and interannual variability}

Many of the observed features of sea-ice distribution and extent, such as the Mertz Glacier Polynya (Williams and Bindoff, 2003), are reproduced by the model (Fig. 1). Generally, modelled winter ice extent agrees well with satellite-derived observations (RMS difference $0.9 \times 10^{6} \mathrm{~km}^{2}$ ). However, modelled ice concentrations are too high, with almost all ice-covered gridcells except those in the MIZ exceeding ice concentrations of $90 \%$. Furthermore, during austral autumn and winter the modelled ice edge is smooth and compact compared to passive-microwave observations. Excessive winter ice concentration within the pack, as simulated by our model, is most likely related to an underestimation of the incoming shortwave radiation in the atmospheric forcing data. This will shortly be investigated by including the calculation of incoming shortwave radiation into the sea-ice model.

During minimum ice extent the modelled ice distribution in the large embayments (including the Weddell and Ross Seas) agrees reasonably well with satellite-derived distributions, while off East Antarctica observed ice extent exceeds that produced in the model by approximately $60 \%$ (Fig. 2). 


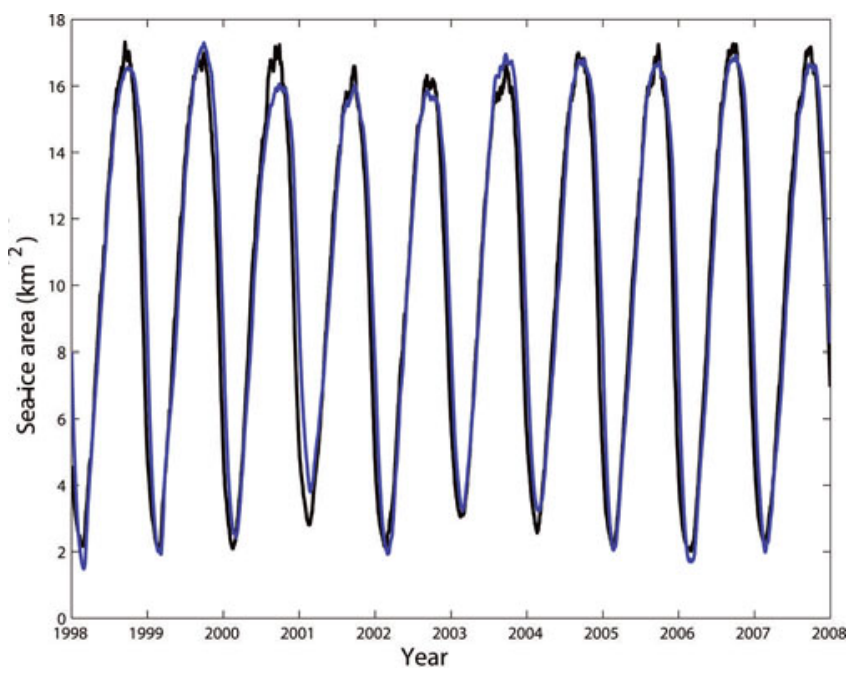

Fig. 3. Modelled sea-ice area (blue) compared to passive microwave observations (black), 1998-2007.

While the model reproduces much of the observed interannual variability in sea-ice area (Fig. 3), it does not reproduce the observed day-to-day changes in ice area. Also, in spring the simulated ice area exceeds the observed. However, modelled spring ice area is within the error limits of passive microwave observations, which have been shown to place the ice edge up to $2^{\circ}$ south of its location as observed from ships (Worby and Comiso, 2004).

\section{Ice-edge speeds and ice velocities}

The ice-edge speeds and ice velocities vary in sign and magnitude around the Antarctic sea-ice zone. Figure 4 shows this for a typical austral winter month. In the sector $340-40^{\circ} \mathrm{E}$, encompassing the eastern Weddell Sea, the iceedge speed is greater than the ice velocity, so this is a region where thermodynamics is dominant in moving the ice edge north. Within this region, there is a sub-region $\left(0-40^{\circ} \mathrm{E}\right)$ where the ice velocity is negative - in agreement with the southward return circulation of the Weddell Gyre - while the ice edge continues to move north. In this sub-region, dynamics is working against thermodynamics.

There are other sectors where the ice velocity is greater than the ice-edge speed. The western Weddell Sea (300$330^{\circ} \mathrm{E}$ ) is an example. In this region, the movement of the ice edge northward is driven by ice advection. However, circum-Antarctic analysis of ice-edge speed and ice velocity shows in most regions that ice velocity is almost $65 \%$ of iceedge speed during June 2001, indicating the dominance of thermodynamic processes in driving the ice-edge location.

To examine the difference in processes operating in the regions where thermodynamics as opposed to dynamics is dominant, two transects are investigated, one at $310^{\circ} \mathrm{E}$ (Fig. $5 \mathrm{a}$ and $\mathrm{b}$ ) and the other at $350^{\circ} \mathrm{E}$ (Fig. 5c and d). In regions where dynamics is driving the ice-edge movement $\left(310^{\circ} \mathrm{E}\right)$ there is significant melt near the ice edge, and thermodynamic ice growth is low but increases to the south where air temperatures are lower (Fig. 5b). However, in regions where thermodynamics is dominant, there is no melt of ice near the ice edge and maximum ice growth occurs in the very thin ice at the ice edge (Fig. $5 d$ ). Thermodynamic ice growth decreases to the south, where thicker ice reduces heat fluxes to the atmosphere.

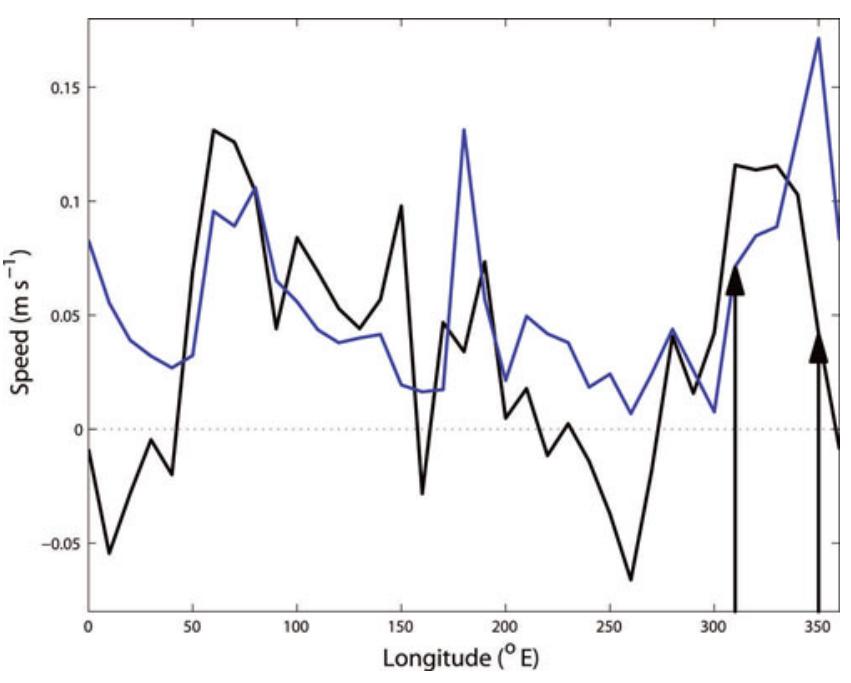

Fig. 4. Ice-edge speed (blue) and ice velocity (black), north positive, in May 2001. Arrows at $310^{\circ} \mathrm{E}$ and $350^{\circ} \mathrm{E}$ are the locations of transects shown in Figure 5.

Although there are three types of melt in CICE4, bottom, top and lateral, they are not of equal importance. When the three types of melt are summed over the year, it is found that bottom melt is dominant, with maximum values eight times larger than those of top melt. By far the smallest is lateral melt, which has maximum values almost eight times less than top melt. This may be because modelled ice concentrations are high within the pack and lateral melt is greatest in low-ice-concentration areas.

The ice-thickness profiles at $310^{\circ} \mathrm{E}$ and $350^{\circ} \mathrm{E}$ vary markedly. At $350^{\circ} \mathrm{E}$ where the ice grows thermodynamically, the profile is one of continuous thinning to zero at the ice edge (ignoring the thinner ice in the coastal polynya region)(Fig. 5c). This is consistent with ice growing thermodynamically and advection not keeping up with the movement of the ice edge, or even being in the opposite direction. At $310^{\circ} \mathrm{E}$ the ice thickness decreases towards the equator, but at a much lower rate, and leaves substantial thickness just south of the MIZ (Fig. 5a). In fact, the maximum ice thickness on this transect is just south of the MIZ. This can be explained by another feature of the Weddell Sea ice-thickness distribution. The east coast of the Antarctic Peninsula is the site of considerable ridging and rafting which produces regions of thick ice adjacent to the peninsula. Masses of this thick coastal ice periodically detach from the coast and drift eastward. This is what happened early in June 2001.

\section{DISCUSSION}

Dynamics provides a direct method of ice-thickness growth, in the form of ridging and rafting. The convergent ice velocities that cause ridging are seen (1) where ice movement is interfered with by land, (2) where the ice velocity decreases because of weakening winds and currents and (3) where there is a shear zone between ice in the Coastal Current and that in the Antarctic Circumpolar Current. Of these mechanisms the interaction with land is the most consistent and causes the most ridging, so the thickest ice is near the coast and moves west with the Coastal Current.

The Weddell Sea, including longitudes $310^{\circ} \mathrm{E}$ and $350^{\circ} \mathrm{E}$, is shown in Figure 6. It shows the freshwater flux on 1 June 2001. The freshwater flux is to the ocean and can be positive 

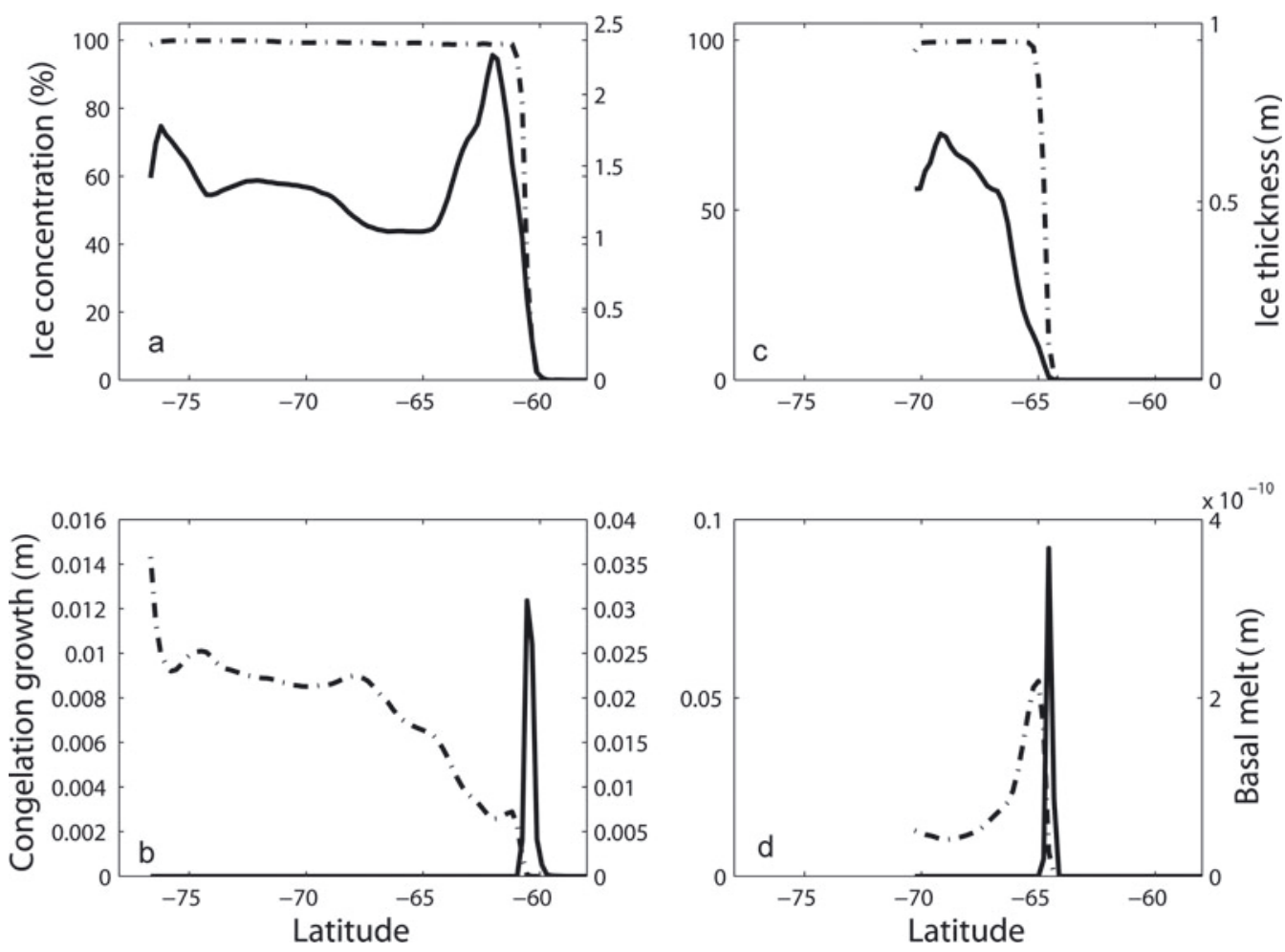

Fig. 5. Transects at $310^{\circ} \mathrm{E}(\mathrm{a}, \mathrm{b})$ and $350^{\circ} \mathrm{E}$ (c, d) on 1 June 2004. (a, c) Ice concentration (dash-dot curve) and ice thickness (solid curve); (b, d) bottom melting (solid curve) and congelation growth (dash-dot curve).

(ice melt) or negative (ice growth). However, precipitation is included and makes the freshwater flux more positive. Despite this complication, ice production is greatest where the air is cold and the ice is thin. It also shows the band of melt at the ice edge between the Antarctic Peninsula and about $335^{\circ} \mathrm{E}$. The ice velocity distribution is reasonably representative but changes quickly with changing wind patterns. It should be noted that the melt occurs north of the ocean freezing contour at $310^{\circ} \mathrm{E}$, but also that ice extends past the freezing point at $350^{\circ} \mathrm{E}$. Even though this is a region dominated by thermodynamics, there is a little melting at the ice edge and a slightly positive freshwater flux.

Our configuration of CICE4 demonstrates the importance of thermodynamic processes in increasing the volume of Antarctic sea ice. We also show the important role of the dynamic process of advection in preparing the way for subsequent ice growth and driving the ice edge northward faster than thermodynamics alone. In some regions this preconditioning of the surface waters is particularly important for the northward movement of the ice edge during the ice growth season. In June 2001 the Weddell Sea (310$330^{\circ} \mathrm{E}$ ) and the seas off the Mawson and Lars Christensen Coast $\left(60-70^{\circ} \mathrm{E}\right)$ show particularly strong northward ice advection (0.11 and $0.13 \mathrm{~m} \mathrm{~s}^{-1}$, respectively), which is greater than the speed of the ice-edge advance $(0.08$ and $0.10 \mathrm{~m} \mathrm{~s}^{-1}$, respectively). The dynamic and thermodynamic processes are closely linked, because dynamic atmospheric processes not only drive the sea-ice dynamics (via advection) but also bring in air masses with modified thermodynamic properties. For example, the greatest northward advection of ice occurs when there is a strong northward component of the winds and the air masses transported by these winds exhibit a low temperature.
The analysis shown here (Fig. 4) clearly identifies large regions where either thermodynamics or dynamics are dominant. However, there are many other regions where this is less clear. This could be a problem with too coarse spatial resolution and/or temporal resolution of the analysis. Higher spatial resolution of the ice-edge speed and ice velocity analysis may be useful. Higher temporal resolution may also improve clarity. It may be useful to attempt to incorporate a representation of ocean waves into the model. It would be useful to assess the importance of not having feedback for the other ocean forcing parameters such as salinity. It is also apparent that the MLD is not uniform over all the Southern Ocean and it might improve the quality of the simulations if MLD could be varied in space as well as time.

\section{CONCLUSIONS}

As part of this study, we used a stand-alone, high-resolution implementation of the CICE4 sea-ice model to examine the seasonal and interannual variability in the equatorward seaice edge, and to evaluate processes affecting it. Our investigation has provided new insight into the balance of dynamic and thermodynamic processes and how they affect the ice-edge location. We found that thermodynamic ice growth dominates over dynamic processes in promoting the northward expansion of the ice edge during austral autumn. However, localized ice advection is the dominant factor in moving the ice edge equatorward during the ice growth season, especially in regions such as the western Weddell Sea. Importantly, the dynamic processes also precondition the upper ocean just north of the ice edge by melt-induced cooling to the freezing point of the ocean mixed layer. The model has allowed us to investigate the ice-production/melt 


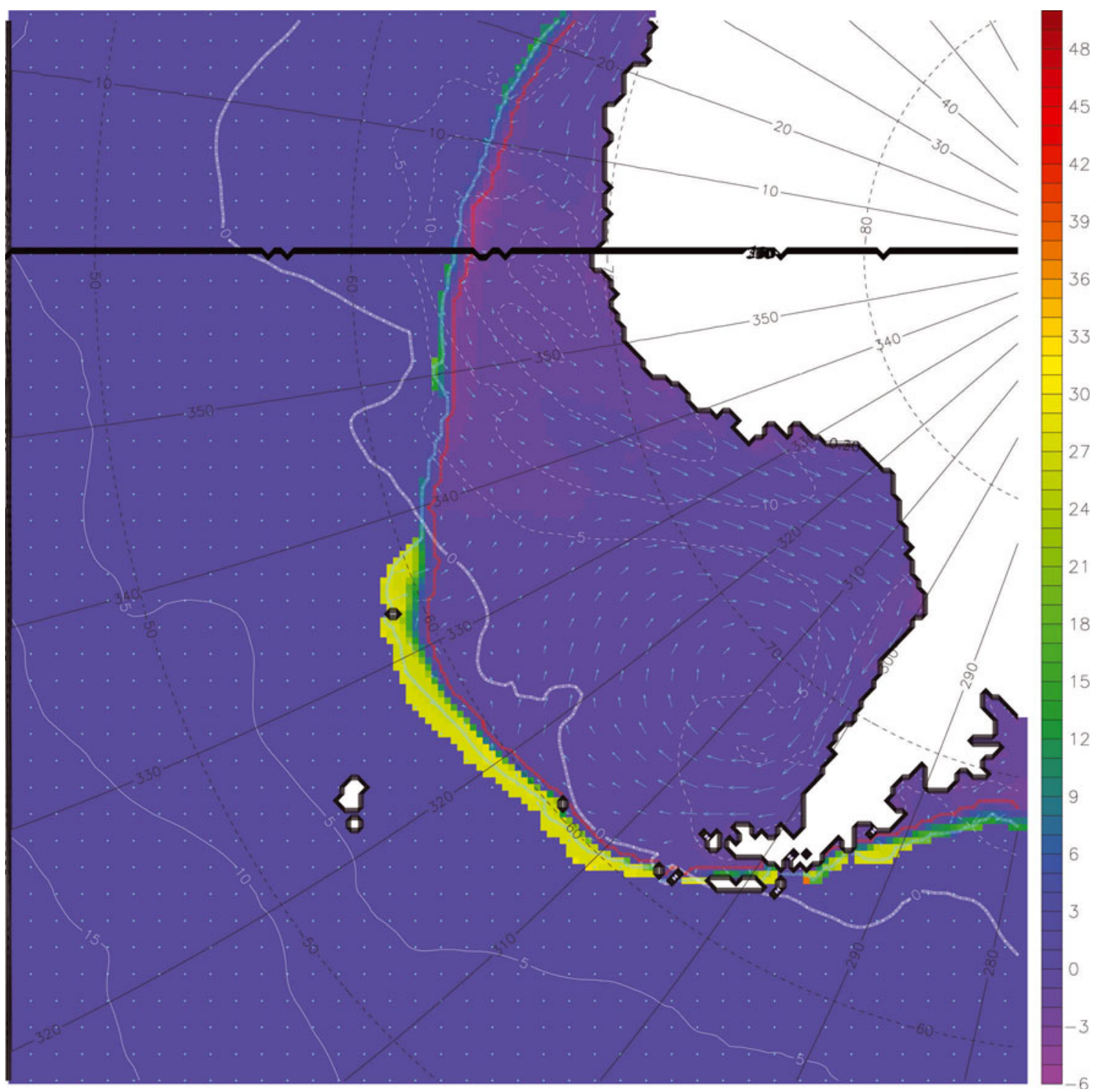

Fig. 6. Freshwater flux in the Weddell Sea on 1 June 2001. Positive values are mostly associated with ice melting, and negative ice values with ice production. The red curve is oceanic freezing point, the white curves are air temperature relative to the local oceanic freezing point, the light blue curve is the ice concentration of $0.1 \%$ and the light blue arrows are the ice velocity.

regions, highlighting the effect of so-called 'freshwater pumps' where sea ice is produced in the south and then advected north where it melts.

\section{ACKNOWLEDGEMENTS}

This research was undertaken on the National Computing Infrastructure facility at the Australian National University, Canberra, which is supported by the Australian Commonwealth Government. The original CICE4 was obtained from the Los Alamos National Laboratory, NM, USA. We thank N. Adams for providing PolarLAPS data and S. Marsland for providing ocean data from AusCOM simulations. SSM/I ice concentrations were obtained from the US National Snow and Ice Data Center, Boulder, CO. The University of Tasmania Quantitative Marine Science Programme and its Postgraduate Office are thanked for travel support. This research was carried out under Australian Antarctic Science project No. 2504, and is supported by the Australian Government's Cooperative Research Centres Programme through the Antarctic Climate and Ecosystems Cooperative Research Centre. W.F. Budd, K. Michael, the scientific editor S.F. Ackley and two anonymous reviewers are thanked for their insightful comments.

\section{REFERENCES}

Bitz, C.M., M.M. Holland, E.C. Hunke and R.E. Moritz. 2005. Maintenance of the sea-ice edge. J. Climate, 18(15), 2903-2921.

Comiso, J.C. and F. Nishio. 2009. Trends in the sea ice cover using enhanced and compatible AMSR-E, SSM/I, and SMMR data. J. Geophys. Res., 113(C2), C02S07. (10.1029/2007JC004257.)

Ebert, E.E. and J.A. Curry. 1993. An intermediate one-dimensional thermodynamic sea ice model for investigating ice-atmosphere interactions. J. Geophys. Res., 98(C6), 10,085-10,109.

Griffies, S.M., M.J. Harrison, R.C. Pacanowski and A. Rosati. 2004. A technical guide to MOM4. Princeton, NJ, National Oceanic and Atmospheric Administration/Geophysical Fluid Dynamics Laboratory. (GFDL Ocean Group Tech. Rep. 5.)

Holland, M.M., C.M. Bitz, E.C. Hunke, W.H. Lipscomb and J.L. Schramm. 2006. Influence of the sea ice thickness 
distribution on polar climate in CCSM. J. Climate, 19(11), 2398-2414.

Hunke, E.C. and J.K. Dukowicz. 1997. An elastic-viscous-plastic model for sea ice dynamics. J. Phys. Oceanogr., 27(9), 1849-1867.

Hunke, E.C. and J.K. Dukowicz. 2002. The elastic-viscous-plastic sea ice dynamics model in general orthogonal curvilinear coordinates on a sphere: incorporation of metric terms. Mon. Weather Rev., 130(7), 1848-1865.

Lipscomb, W.H. and E.C. Hunke. 2004. Modeling sea ice transport using incremental remapping. Mon. Weather Rev., 132(6), 1341-1354.

Loeb, V. and 6 others. 1997. Effects of sea-ice extent and krill or salp dominance on the Antarctic food web. Nature, 387(6636), 897-900.

Lubin, D. and R. Massom. 2006. Polar remote sensing. Volume 1: Atmosphere and oceans. Chichester, Springer-Praxis.
Redler, R., S. Valcke and H. Ritzdorf. 2010. OASIS4 - a coupling software for next generation earth system modelling. Geosci. Model Dev., 3(1), 87-104.

Scambos, T.A., T.M. Haran, M.A. Fahnestock, T.H. Painter and J. Bohlander. 2007. MODIS-based Mosaic of Antarctica (MOA) data sets: continent-wide surface morphology and snow grain size. Remote Sens. Environ., 111(2-3), 242-257.

Thomas, D.N. and G.S. Dieckmann,, eds. 2009. Sea ice. Second edition. Chichester, Wiley-Blackwell.

Williams, G.D. and N.L. Bindoff. 2003. Wintertime oceanography of the Adélie Depression. Deep-Sea Res. II, 50(8-9), 1373-1392.

Winton, M. 2000. A reformulated three-layer sea ice model. J. Atmos. Oceanic Technol., 17(4), 525-531.

Worby, A.P. and J.C. Comiso. 2004. Studies of the Antarctic sea ice edge and ice extent from satellite and ship observations. Remote Sens. Environ., 92(1), 98-111. 